\title{
Telefarming: When push comes to shelve in responding to COVID-19
}

\author{
Salina Brown ${ }^{\mathrm{a}} *$ and Kathleen Liang $\mathrm{b}$ \\ North Carolina Agricultural and Technical State University
}
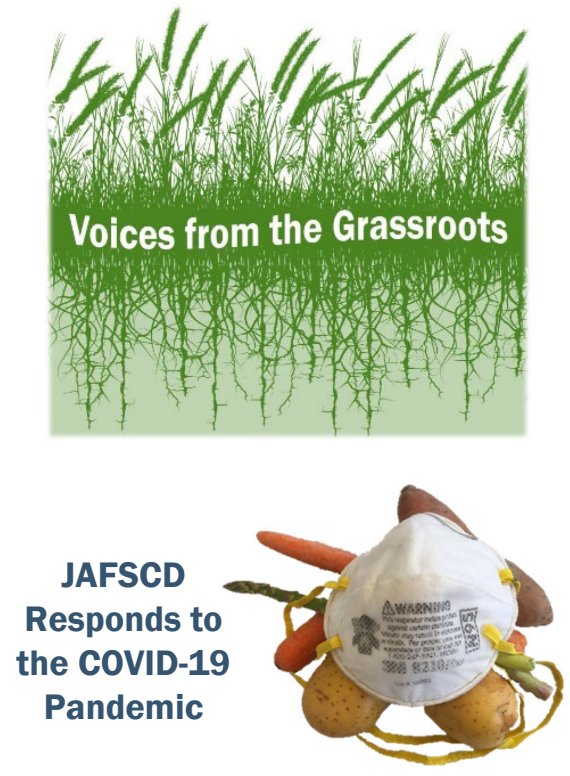

Submitted April 20, 2020 / Published online May 6, 2020

Citation: Brown, S., \& Liang, K. (2020). Telefarming: When push comes to shelve in responding to COVID-19. Journal of Agriculture, Food Systems, and Community Development, 9(3), 45-48. https://doi.org/10.5304/jafscd.2020.093.030

Copyright (C) 2020 by the Authors. Published by the Lyson Center for Civic Agriculture and Food Systems. Open access under CC-BY license.

$\mathrm{C}$ OVID-19 has introduced new ways of completing jobs virtually. According to the Bureau of Labor Statistics, over 22 million Americans filed for unemployment through mid- April 2020 (Long, 2020). Approximately 747,000 citizens in North Carolina alone have been forced out of work due to social distancing requirements (Chiwaya \& $\mathrm{Wu}$, 2020). While some workers have been able to continue working at home or be compensated during the pandemic, such as many faculty and staff working for schools, it has been devastating for small business owners, including farmers, to handle

a* Corresponding author: Salina Brown is a Goldsboro native, went to Goldsboro High School, and received a BS degree in English from North Carolina Agricultural and Technical State University. She is currently working at the Small Farm Unit of the Center for Environmental Farming Systems, located on the Cherry Research Station in Goldsboro, NC. She can be contacted at sabrown2@aggies.ncat.edu.

${ }^{\mathrm{b}}$ Dr. Kathleen Liang, W. K. Kellogg Distinguished Professor of Sustainable Agriculture and Director, Center for Environmental Farming Systems, North Carolina Agricultural and the pressure and stress.

During this crucial time, workers must think critically and creatively to fulfill necessary tasks. However, one job, in particular, has been deemed to be essential to our daily life and one of the most critical roles in the country: work in agricultural and food industries. The most recent U.S. Department of Agriculture farm labor report (USDA Economic Research Service, 2020) indicates that hired farmworkers represent less than 1 percent of all U.S. wage and salary employees. However, hired farmworkers contribute to a variety of jobs beyond

Technical State University, College of Agriculture and Environmental Sciences, Greensboro, NC USA. Dr. Liang received her MS and PhD in Agricultural Economics from Purdue University. She is the founder of Dollar Enterprise experiential learning in entrepreneurship and is an awardwinning scholar of interdisciplinary research, teaching, and outreach focusing on entrepreneurship and innovation, food systems, multifunctional agriculture, and sustainable community development. She can be reached at cliang@ncat.edu. 
working in the field or nursery. They contribute to the food system from production to the supply chain-performing inspections and working in testing labs, certification programs, educational programs, and customer services. COVID-19 has had a significant impact on agriculture and food security. The challenge of feeding people well while maintaining safety has become a major issue. Developed by my supervisor and me (Salina) is the work of telefarming, an old trade mixed with modern communication that can assist those who want to grow produce but may not have much experience in farming.

Although a Goldsboro native, I have not always been familiar with agriculture. I had one summer of experience along with a horticultural class to back me up on my knowledge about how to grow produce. During the summer of 2018, I had an apprenticeship with the Small Farm Unit of the Center for Environmental Farming Systems ${ }^{1}$ (CEFS) in Goldsboro, NC; its co-director and research principal investigator, Dr. Chyi-Lyi (Kathleen) Liang, became my supervisor. CEFS is a three-way partnership between North Carolina Agricultural and Technical State University, North Carolina State University, and North Carolina Department of Agriculture and Consumer Services. This partnership has been around for 25 years with a mission to design, develop, and promote sustainable practices for farming and community development. The Small Farm Unit is a 30-acre (12hectare) research farm divided into halves: 15 acres (6 ha) are certified organic, and 15 acres are not, although we have adopted organic practices throughout the unit. There are two small high tunnels on the certified organic side, and three large commercial-scale high tunnels in the nonorganic certified side. We have further divided the production area into multiple $1 / 2$-acre plots, and we grow mixed organic fruits and vegetables on different plots to simulate small-scale farming activities. Generally speaking, many small-scale farmers grow mixed fruits and vegetables to diversify their income sources.

The production season at the Small Farm Unit runs between March and December of each year.
We start planning and preparation in January, and we start growing transplants of some vegetables in February. One of our unique features is that we produce 20 to 25 varieties of organic specialty vegetables each year using multiple plots to train N.C. farmers to target ethnic markets to get higherprice margins. Through the experience of working on a $1 / 2$-acre plot, I learned to use hand tools and light equipment such as seeder, weed whacker, greens harvester, and zero-turn mower to seed, weed, and harvest. All of our fresh produce is donated to local charities such as soup kitchens and faith-based organizations such as the Salvation Army. Beyond working as an apprentice to support farming activities, I also completed yard work around the farm and gained enough knowledge to be of assistance in creating training-related materials. However, I was in no way, in my personal opinion, ready to take on farming alone. So, after Dr. Liang told me that, due to the COVID-19 pandemic, I would be on the farm by myself supporting essential activities, with assistance only from time to time, I panicked.

When COVID-19 hit in March 2020, we had already finished producing more than 3,000 transplants in the greenhouse in February and were waiting for spring field production. The North Carolina Department of Agriculture and Consumer Services issued a lock-down order in late March, canceling all visiting and non-essential activities at the research farm, including the Small Farm Unit. This presented a tough question that Dr. Liang needed to respond to immediately: should we continue our research operations? If we abandoned the research transplants, we would lose a significant volume of data and records to share with farmers. If we continued our research projects during the lock-down, how would we proceed, with Dr. Liang staying at home in Goldsboro and me living in Goldsboro?

Dr. Liang has always believed in me, knowing my background as a technical writer. She appreciated that my primary goals have been assisting with economic development and food security for my community. She was inclined to do whatever she could to help both my community and me, because

\footnotetext{
${ }^{1}$ https://cefs.ncsu.edu/
} 
she has these same goals for a much broader audience. With my goals in mind and eager to show my mentor that I respected her wisdom and advice, I was learning to farm from scratch. Trusting me but understanding my limited experience, Dr. Liang assured me of no worries by saying that some staff would be on-site to provide assistance and support.

Starting in February as a research technician, I was able to harvest and donate our vegetables grown since fall 2019, as I already knew how to do that. I harvested 3 to 4 crates a day, weighed them, and donated the produce to a local soup kitchen on Fridays, accompanied by Dr. Liang. I also did yard work and kept a weekly report where I recorded the growth of the transplants and noted any changes until they made it to their new homes

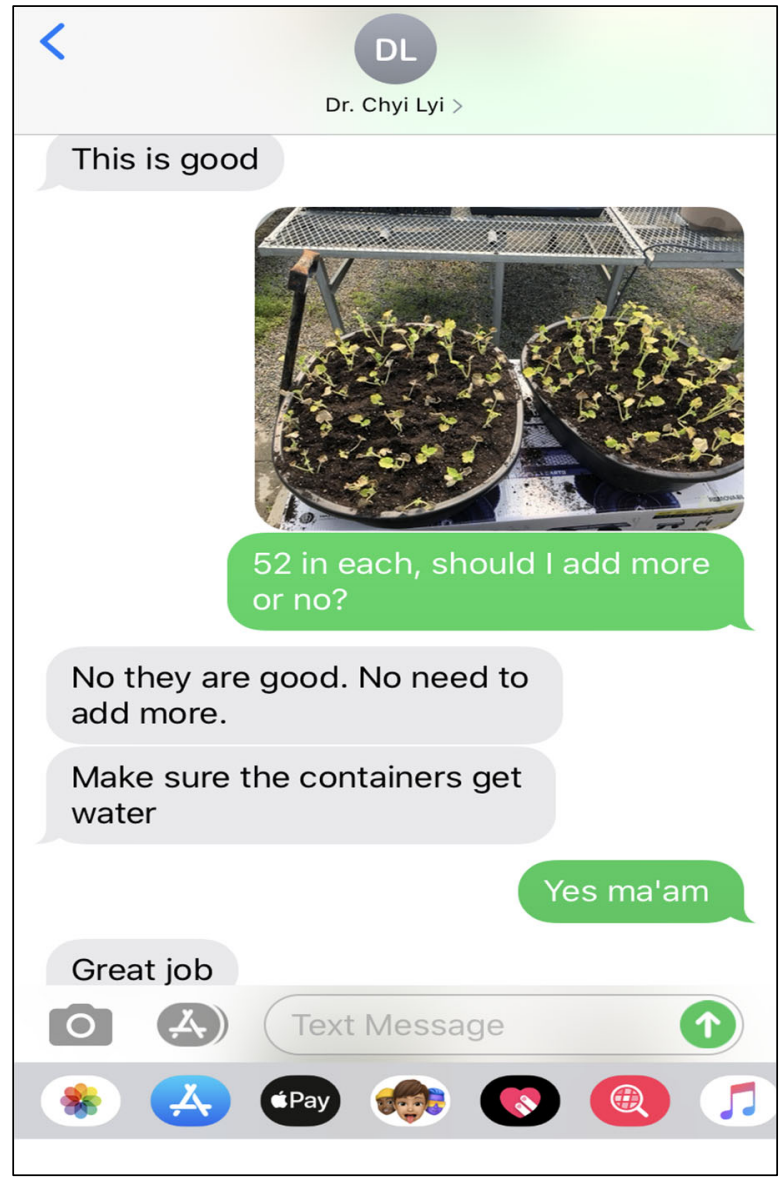

Communication by text and photo guided the on-site farmer novice to be successful in saving seedlings prior to transplanting them, with guidance from the off-site manager. come April. If everything went according to plan, we would have a bountiful and beautiful spring crop in April and May, maybe lasting into June and July.

The only issue with this beautifully crafted game plan is that COVID-19 caused a travel ban throughout the country, disallowing anyone deemed not essential. This rule left me alone in April with thousands of transplants that had no specific final locations to grow at the Small Farm Unit. My limited experience in farming hindered me from being able to finish preparing the spring plot for the transplants. Dr. Liang was aware of the issue, but as a food security advocate, she was not about to let the greenhouse starters die. I witnessed her sending numerous emails to see if she could get some sort of assistance to get the plots ready, but all she received was crickets-no response. During the few days of waiting hopelessly for responses, she asked me to continue doing my reports. Some of the transplants appeared to be fine, but from my summer experience, I knew the gourd plants were not looking too good.

After sending a picture of the gourd seedlings to Dr. Liang, she called and told me that we needed to do something quickly. She immediately gave me step-by-step instructions over the phone and via text messages on how we were going to save the gourds. All of our communications are through phone calls and messages. I was told to find buckets and crates, fill them up with mixed soil, and put the gourd seedlings into their intermediary new growing environment. I mixed garden soil along with the soil originally used for the transplants into the containers and then used Dr. Liang's "two fingers and two inches" rule to place the transplants into their intermediary new growing environment. The two fingers rule created a deep enough hole for the transplants' roots to grow, and two inches apart rule created the space needed for the transplants to grow without stealing the other starters' nutrients. To make sure this was done correctly and to preserve the life of the gourds, I had to manually switch and move the buckets and crates from the watering side of the greenhouse to the dry-bed side to let them drain while we identified beds to put them in the ground. Very soon, I ran out of buckets and crates. Dr. Liang told me to 
gather similar containers around the farm, and I cleaned the containers to get rid of the spider webs, dirt, and leaves. Next, I had to monitor the automatic watering system in the greenhouse and continue to switch buckets, crates, and containers to the dry-bed side of the greenhouse. I needed to make sure to drain the excess water out of the transplant sheets on the tables so that the roots would be strong enough for their next transition into the beds.

To be sure that I was doing everything correctly, I took photos and sent them to Dr. Liang for approval. In two days, I was able to save over 1,200 gourd plants with the help of Dr. Liang's telecommunication efforts.

Through this experience, I learned how to recognize if a plant is diseased, lacking moisture, or dehydrated, and the importance of mixing soil for fertilization purposes and how to move transplants properly. I also learned that anyone can farm if you have the patience, diligence, and a telephone.

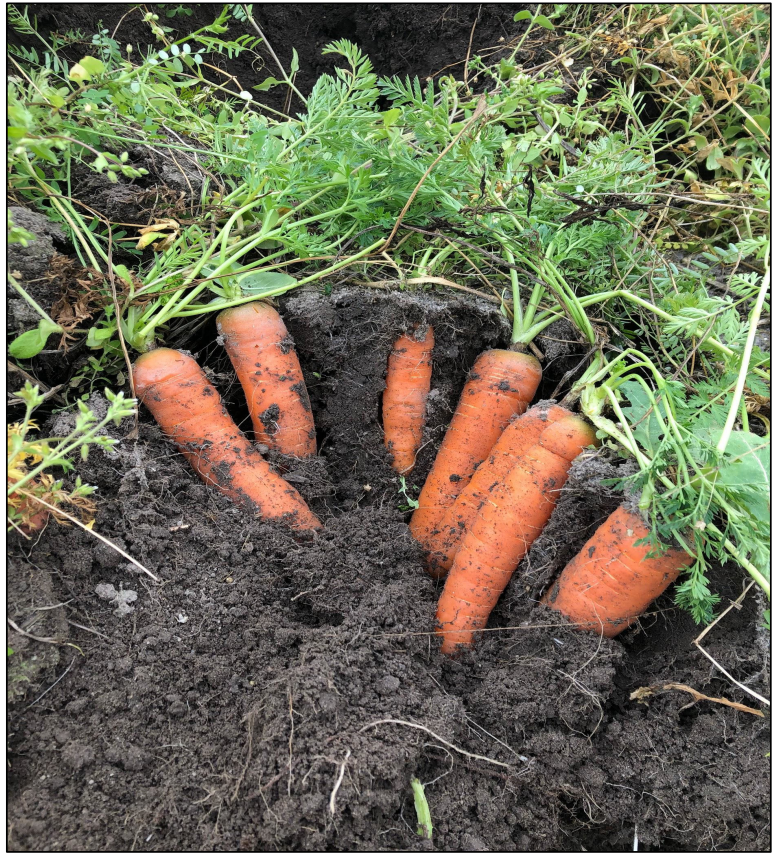

Carrots produced at the Center for Environmental Farming System's Small Farm Unit since fall 2019.

\section{References}

Chiwaya, N., \& Wu, J. (2020, April 14/Updated April 30). Unemployment claims by state: See how COVID-19 has destroyed the job market. NBC News. Retrieved from https://www.nbcnews.com/business/economy/unemployment-claims-state-see-how-covid-19-has-destroyed-job$\underline{\mathrm{n} 1183686}$

Long, H. (2020, April 16). U.S. now has 22 million unemployed, wiping out a decade of job gains. The Washington Post. https://www.washingtonpost.com/business/2020/04/16/unemployment-claims-coronavirus/

U.S. Department of Agriculture, Economic Research Service. (2020, April 22). Farm labor. Retrieved from https://www.ers.usda.gov/topics/farm-economy/farm-labor/ 